\title{
The Swing-Arm Trellis for Sultana Grapevine Management
}

\author{
P. R. CLINGELEFFER and P. MAY \\ Respectively Experimental Officer and Chief Research Scientist, CSIRO Division of Horticultural Research, Private Mail Bag, Merbein, Victoria,
} 3505, Australia and G.P.O. Box 350, Adelaide, South Australia, 5001, Australia.

Technical assistance given by R. J. G. Polkinghorne is acknowledged.

\begin{abstract}
The swing-arm trellis, designed to improve mechanical harvesting of Sultana grapevines used for raisin or wine production and to allow partial mechanization of pruning, is described. The trellis consists of seven wires, i.e. a cordon-wire and three wires each spaced evenly in the horizontal and vertical plane and supported by triangular frames attached to the trellis posts. The vines are pruned to cordons that produce shoots that grow upward and attach to the vertical wires. For use as replacement canes, these shoots are placed horizontally by rotation of the frames.

The yield of Sultana vines trained in this way was equal to or better than that of control vines trained in the standard manner with canes twisted around a single wire. Over four seasons, total yield was 1,31 times more for fresh fruit and 1,25 more for sugar. The yield differences occurred mainly in two seasons and were due to the combined effects of more nodes, better bud burst, more fruitful nodes and, consequently, more bunches. The advantages of managing vines trained on the swing-arm trellis are discussed.
\end{abstract}

The Sultana (syn. Sultanina, Thompson Seedless) is the most important grape variety in Australia, producing annually about 60000 tonnes of raisins, while a further 60000 tonnes of fresh grapes are used for wine. Sultana vines are grown in the irrigated vineyards of the Murray Valley, usually at $3,3 \times 2,7 \mathrm{~m}$ row $\times$ vine spacing. They carry from six to twelve canes of ten to twenty nodes each. The canes are tightly wrapped around a single cane wire or two wires, spaced either $0,3 \mathrm{~m}$ apart in the horizontal or about $0,4 \mathrm{~m}$ apart in the vertical plane. Often a further foliage wire is placed about $0,4 \mathrm{~m}$ above the level of the (upper) cane wire that is usually situated 0,8 to $1 \mathrm{~m}$ above ground level. Wooden or steel posts spaced 8 to $11 \mathrm{~m}$ apart support the trellis wires.

Cane-pruning is generally considered to be the only method suitable for Sultana vines because the basal nodes are not fruitful. In contrast to spur-pruning, it has not been possible so far to fully mechanise cane-pruning although pruning-time can be reduced by loose instead of tight attachment of the canes (May 1965), by using the "split system" of training where canes and replacement shoots are spatially separated (May et al. 1978), or by using the cane/spur system where most of the crop is borne on long, machine-pruned spurs on two-year-old canes (May \& Clingeleffer 1977).

Fresh Sultana grapes are now harvested routinely by machine when used for wine making, but not when used for producing raisins, although promising results have been obtained in experiments (May et al. 1974). Trellis drying (May \& Kerridge 1967) followed by collecting the raisins with a harvester requires less hand-labour than hand-picking of the fresh fruit and drying on racks (May 1976). However, harvest-pruning, which forms part of the trellis-drying technique, may cause a non-cumulative, annual loss of yield of the order of $10 \%$ (Scholefield, May \& Neales 1977).

A training system for Sultana vines, for which we propose the name swing-arm trellis, promises to overcome the high cost of hand-pruning and hand-harvesting. It is based on the canopy concept developed by Dunn (1974) for raspberries, and is intended for use in standard vineyards for both wine grape and raisin production.
The purpose of the experiment reported in this paper was to test vine response to training on the swing-arm trellis, in particular whether vineyard yields are maintained prior to further development of the system.

\section{MATERIALS AND METHODS}

The swing-arm trellis: The concept of the swing-arm trellis is shown in Fig. 1. It consists of seven wires, the "cordon-wire" attached to the trellis posts at $1,0 \mathrm{~m}$ above ground level and six additional wires supported by triangular frames. These have two arms of $0,9 \mathrm{~m}$ length, joined at right angles and braced. Each post carries such a frame that is prevented from pivoting by a pin. Each arm of the frame holds three wires spaced at $0,0,0,3$ and $0,6 \mathrm{~m}$ from its outer edge, so that three wires lie in a horizontal and three in a vertical plane. During winterpruning the frames are rotated through $90^{\circ}$, whereby the previously vertical arms become the horizontal arms and face into the interrow-space opposite to that of the previous season's horizontal arms. These in turn become the vertical arms.

The replacement shoots of each vine arise on bilateral cordons attached to the cordon-wire, and tend to grow upward with the support of the wires attached to the vertical arms of the frame. The rotation of the frames places these shoots, i.e. the new canes, in a horizontal position at right angles to the direction of the row. Their pruning is then completed by cutting these canes to length along the outermost wire and by the repositioning of some of the canes.

The shoots arising from these canes produce the crop. The canes are severed during harvest-pruning if the grapes are to be dried on the trellis, or cut off in winter if the fruit is to be hand-picked and dried on racks. Once the severed canes are removed and the frames rotated during winter, the now empty wires of the vertical arms are ready to hold the new spring growth developing on or near the cordon.

In the present experiment, the swing-arm trellis was installed in two stages. In winter 1975 , the existing $\mathrm{T}$ trellis, comprising wooden posts at $7.5 \mathrm{~m}$ spacing and two 
FIG. 1.

Views of vines trained on swing-arm trellis (S):

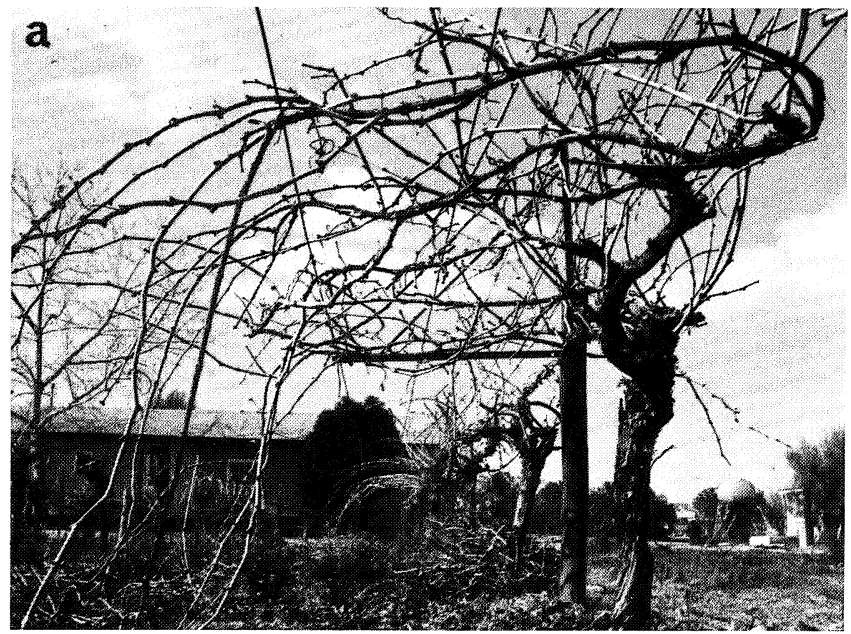

(a) Before winter-pruning. Note cordon on cordon-wire and two-year-old canes with their shoots on horizontal wires.

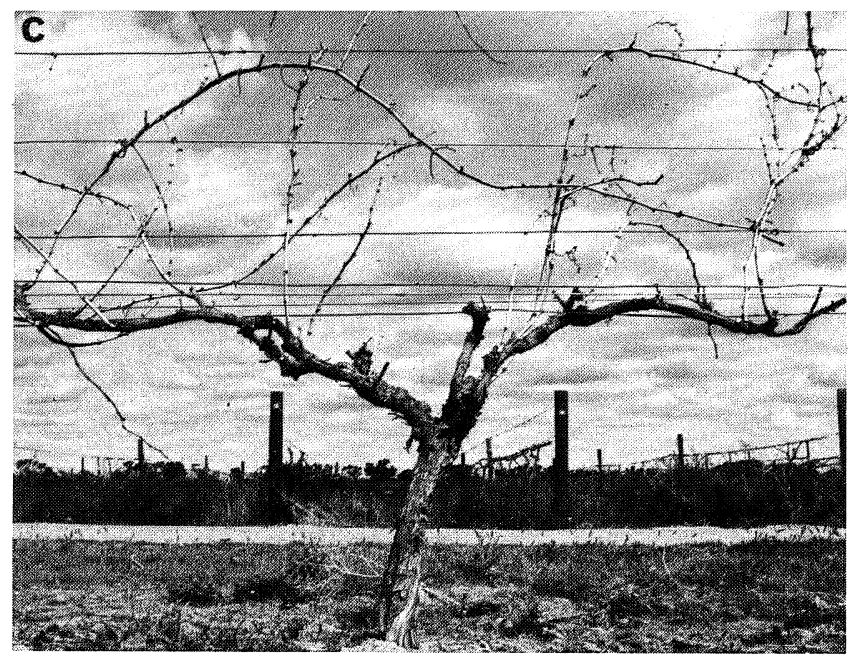

(c) After removal of spent wood, with replacement canes on wires of vertical arm before rotation of the frame.

cane-wires at $0.9 \mathrm{~m}$ height and $0,3 \mathrm{~m}$ apart, was converted to a trellis with a cordon-wire at $1,0 \mathrm{~m}$ height and the horizontal arms of the frames with their three wires at $1,15 \mathrm{~m}$ height. During the next winter, the complete frames were installed at that height, but they were lowered to the height of the cordon-wire in winter 1978. The arms of the frames consisted of $25 \times 25 \times 3 \mathrm{~mm}$ angle-iron and the brace of $10 \mathrm{~mm}$ diameter mild steel rod.

The vines: The experiment consisted of Sultana vines of clone H4 (Antcliff \& Hawson 1974), planted in 1964 in the vineyard of the CSIRO Division of Horticultural Research, Merbein, Vic. For practical reasons, the trellis was installed in the southern boundary-row of a field with NW-SE row direction and $3,3 \times 2,5 \mathrm{~m}$ row $\times$ vine spacing. Up to the start of the experiment, the vines had been pruned to eight canes of about 14 nodes, distributed over the two wires of the T-trellis. In winter 1975, when the experiment was started, two good-quality two-year-

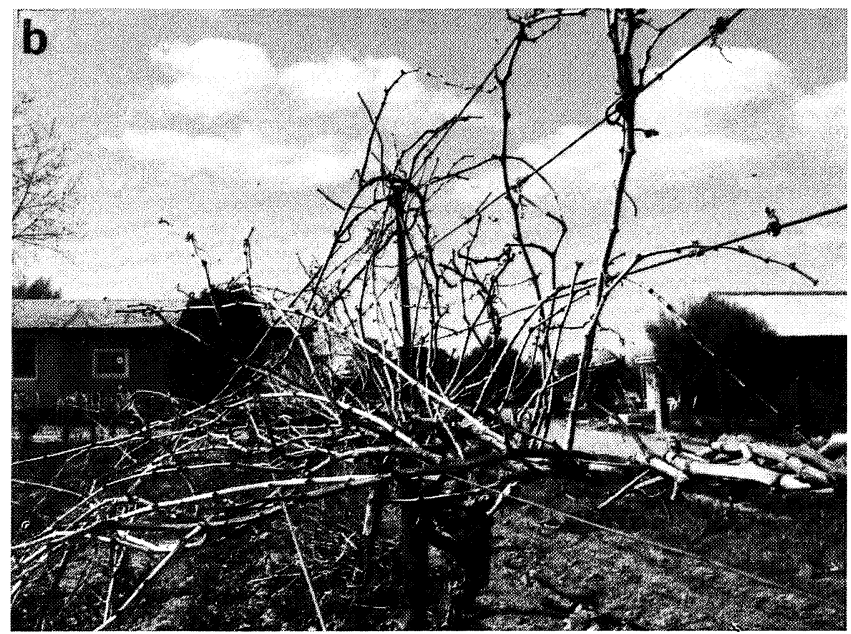

(b) Before winter-pruning. Note the separation of the (horizontal) fruiting wood and (vertical) replacement canes. The canes wrapped around the cordon-wire (foreground) come from the adjacent control $(\mathrm{N})$ vine.

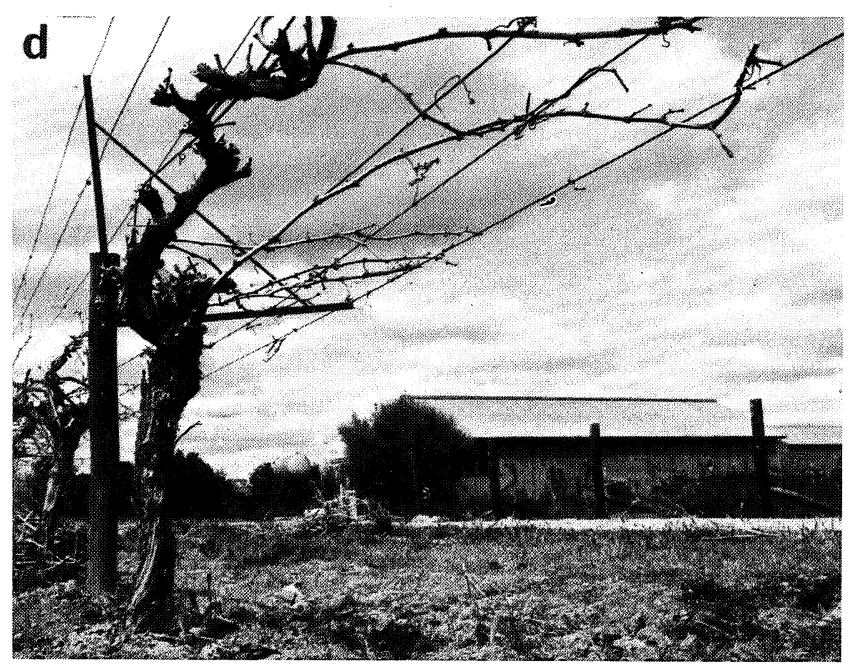

(d) After winter-pruning. Note that the canes in $(b)$ and (d) point in the opposite direction.

old canes that filled the wire and carried several oneyear-old canes were selected to form the bilateral cordon of each vine to be trained on the swing-arm trellis. Eight one-year-old canes from this cordon and, where necessary, from other parts of the vine were laid across the horizontal wires.

The experiment extended over four seasons* apart from the season of conversion. It contained two treatments, arranged as single-vine plots of six randomized blocks. The control vines $(\mathrm{N})$ were pruned to eight canes that originated at the crown of the vine, had varying numbers of nodes and were twisted around the cordonwire. The swing-arm vines (S) were also pruned to eight canes of varying length and to some spurs as source of replacement shoots. Both canes and spurs originated at or near the cordon.

The wires of the swing-arm trellis ran continuously along the S-vines and the $\mathrm{N}$-vines. The horizontal arms *Seasons extend over two calendar years; they are labelled by the year of harvest. 
pointed into the space outside the field in seasons 1976 , 1978 and 1980 and into the interrow-space in 1977 and 1979.

Measurements: The numbers of nodes, shoots and bunches were counted each spring, using the method of the Merbein Bunch Count (Antcliff et al. 1972). In spring of seasons 1977, 1978 and 1980, the time of bud burst was also noted and the results expressed as the mean date of bud burst and as frequency of burst nodes at each time of observation. Fresh weight of fruit per vine and sugar concentration of sample berries were measured each season, while total titratable acidity and $\mathrm{pH}$ were determined in 1980 only. During winter-pruning, the one-yearold prunings were weighed in the last three seasons, and the numbers and distribution of available replacement canes were recorded in 1979 and 1980 , together with the distribution of the one-year-old pruning wood and the amount of older pruning wood removed.

\section{RESULTS}

Observations during spring: The S-vines carried more nodes on their canes than the $\mathrm{N}$-vines in two of the four seasons (Fig. 2a). As all vines were given eight canes, this difference was due to variable node numbers per cane (Table 1). In addition, the cordons of the S-vines had more nodes and produced more non-cane shoots than the crowns of the $\mathrm{N}$-vines. Averaged over the four seasons, the S- and $\mathrm{N}$-vines had 142 and 108 shoots respectively; $113(80 \%, \mathrm{~S})$ and $97(90 \%, \mathrm{~N})$ originated on canes while $29(\mathrm{~S})$ and $11(\mathrm{~N})$ came from spurs or nodes older than one year.

The increased number of cane-shoots on S-vines was due not only to the greater number of nodes per cane but also to a greater proportion of nodes that burst (Fig. 2b). This is further illustrated in Fig. 3 I where per cent bud burst at the first 14 nodes is plotted, together with the
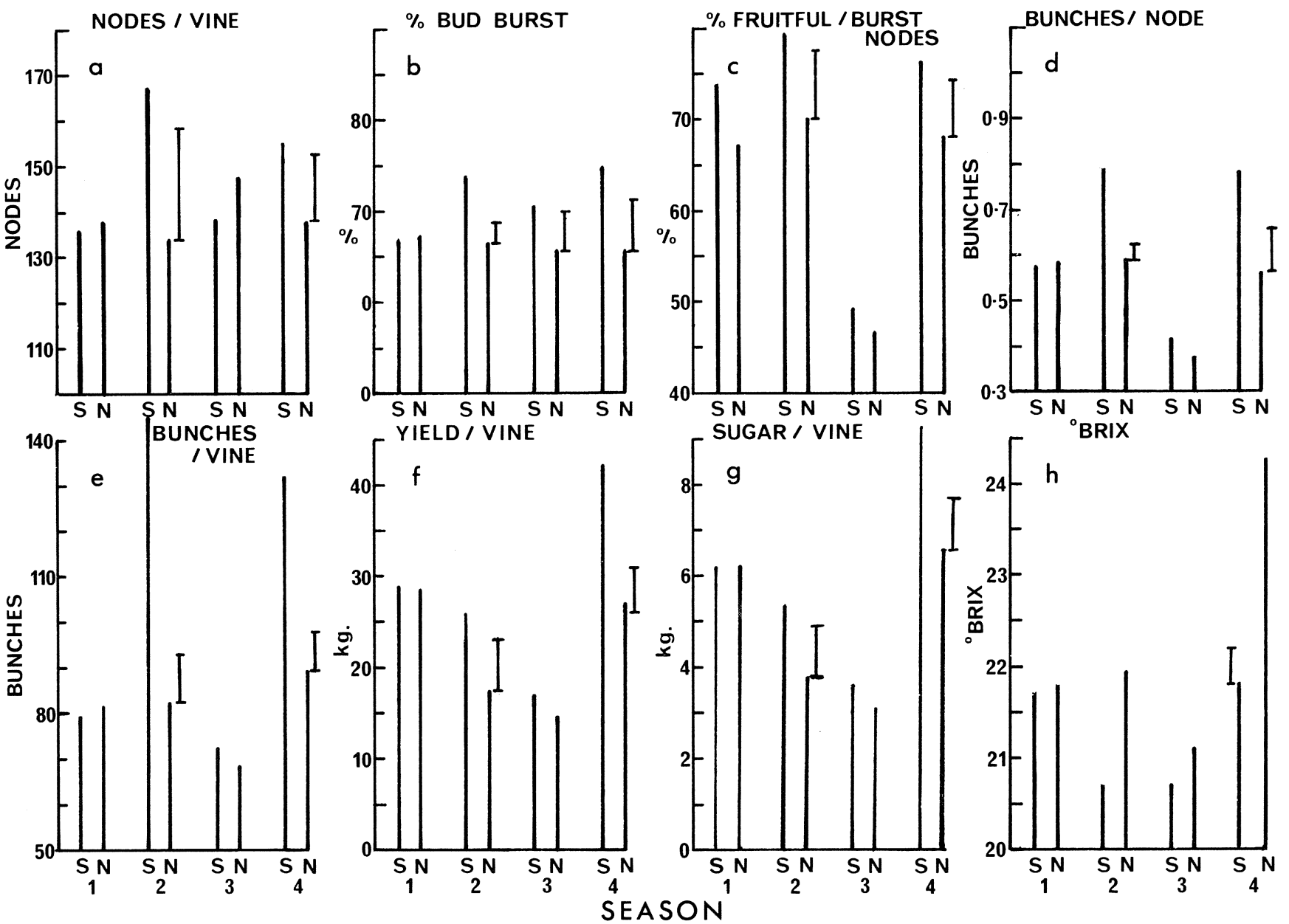

Fig. 2.

Nodes per vine (a), \% bud burst $(b), \%$ fruitful/burst nodes (c), number of bunches per node $(d)$ or per vine $(e)$, yield of fresh fruit per vine $(f)$, yield of sugar per vine $(g)$ and sugar concentration of a berry sample $\left({ }^{\circ} \mathrm{Brix}, \mathrm{h}\right)$ for $\mathrm{S}$ - and $\mathrm{N}$-vines during four seasons. Least significant differences between the treatments $(P=0,05)$ are shown by bars. $\mathrm{S}=$ swing-arm vine with transverse canes $\mathrm{N}=$ normal, cane-pruned vine

S. Afr. J. Enol. Vitic., Vol. 2. No. 2. 1981 
TABLE 1 .

Frequency of canes occurring in four classes of varying number of nodes per cane for $\mathrm{S}$ - and $\mathrm{N}$-vines in each of four seasons. 48 canes per treatment per season.

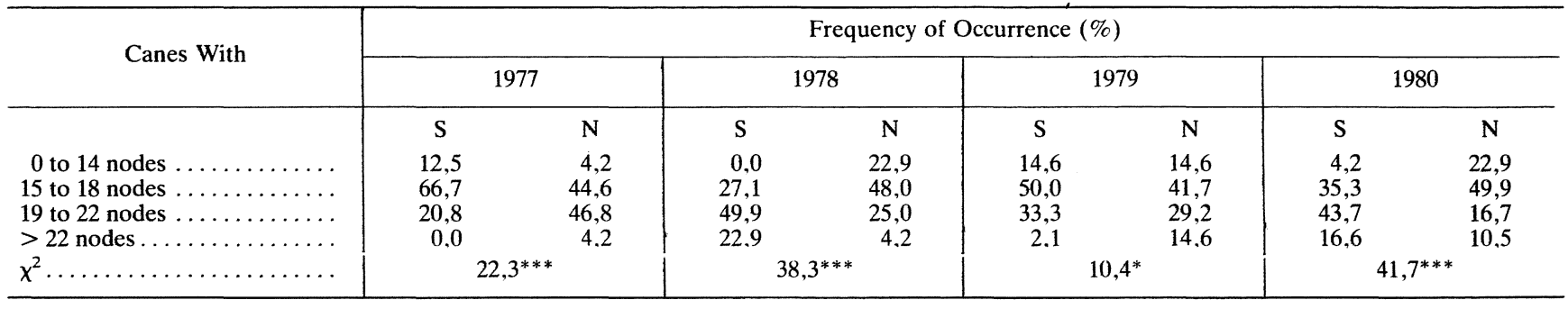
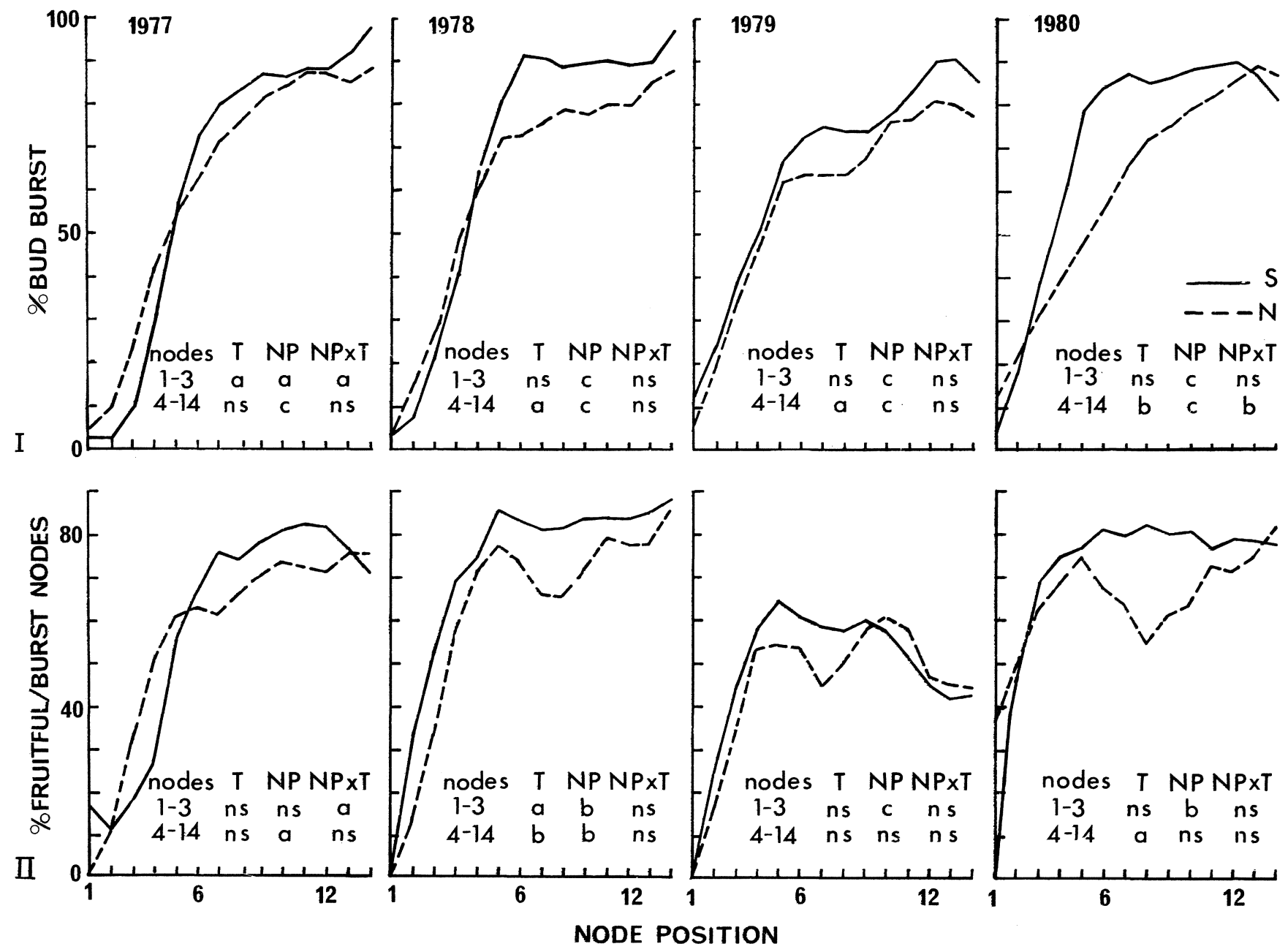

Fig. 3.

Per cent bud burst (I) and \% fruitful/burst nodes (II) for S- and $\mathrm{N}$-vines during four seasons. Significance levels (ns $=$ not significant, $a, b, c$, significant at $5 \%, 1 \%$ and $0,1 \%$ respectively) for differences between treatments $S$ and $N(T)$, node position (NP) and their interaction (NP $\times$ T) are shown for nodes $1-3$ and 4-14.

statistical significance of the differences between treatments, node positions and their interaction, calculated separately for nodes $1-3$ and 4-14 because of widely varying variances. Buds burst more frequently on $\mathrm{S}$-canes mainly in the middle, most fruitful region of the canes.

The cane-nodes that burst were more fruitful on the Sthan on the $\mathrm{N}$-vines, although the differences reached significance $(P<0,05)$ in only two seasons (Fig. 2c, Fig. 3 II). Mean number of bunches per node followed a similar trend (Fig. 2d). The values for bunch number per vine (Fig. 2e) also include the bunches on non-cane shoots. These amounted to 1,3 to $12,5 \%$ (mean $7,8 \%$ ) on the S-vines and to 1,0 to $3,2 \%$ (mean $2,8 \%$ ) on the $\mathrm{N}$-vines during the four seasons. 


\begin{tabular}{|c|c|c|c|c|c|c|c|c|c|}
\hline MEAN DAY & $\mathrm{S}$ & $N$ & LSD & $\mathrm{S}$ & $N$ & LSD & $\mathrm{S}$ & $N$ & LSD \\
\hline OF BURST & $13 \cdot 1$ & $13 \cdot 0$ & ns & $7 \cdot 8$ & $11 \cdot 6$ & $2 \cdot 6$ & $10 \cdot 1$ & $11 \cdot 5$ & 1.3 \\
\hline
\end{tabular}

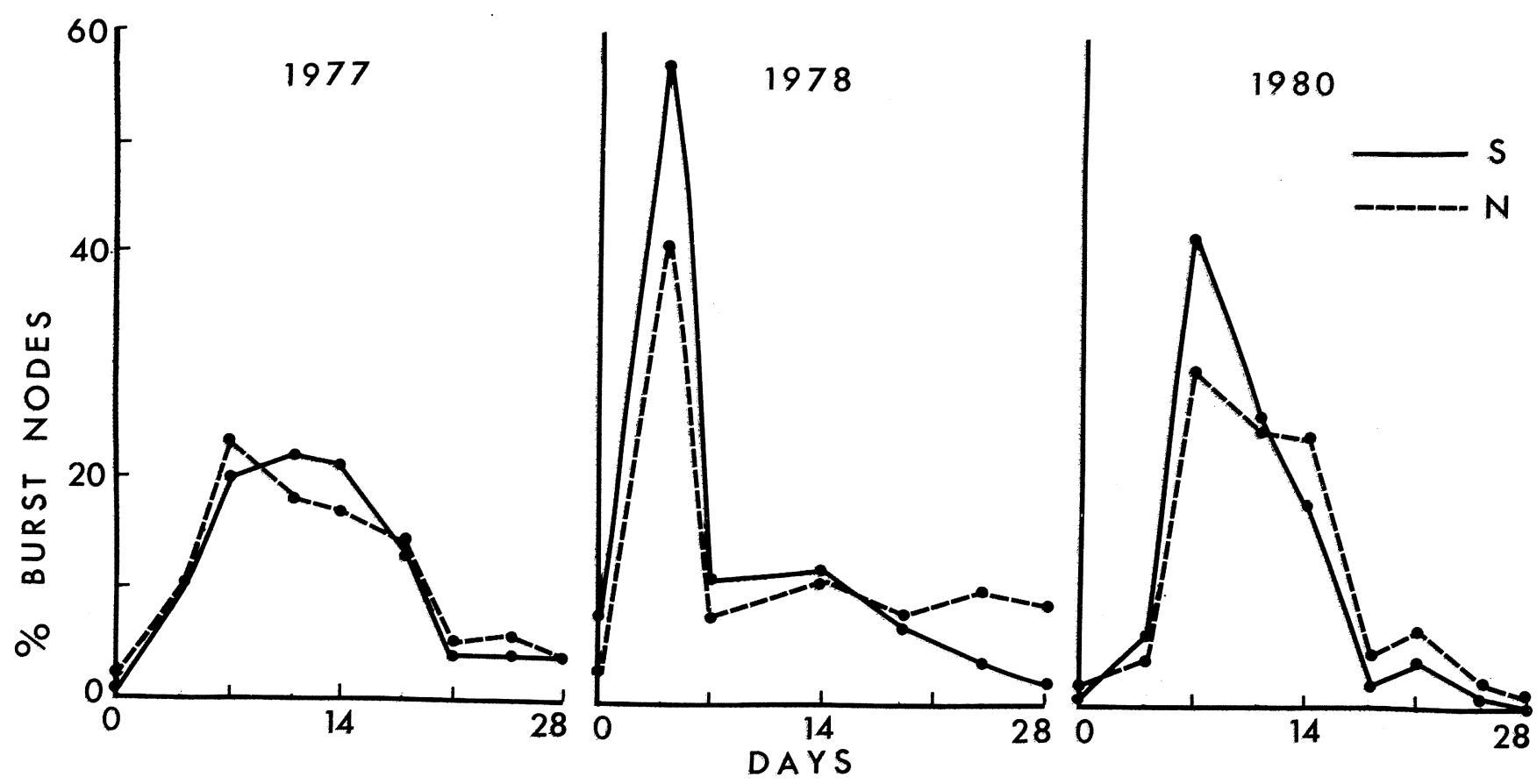

FIG. 4.

Frequency of bud burst on S- and N-vines on the day when burst was first observed and on eight subsequent dates, together with mean days of burst per vine after that date. Seasons 1977, 1978 and 1980.

Bud burst was first noted on 3 September 1977, 26 August 1978 and 3 September 1980. Figure 4 shows for each season the mean day of bud burst per vine after these dates and the percentage of buds that had burst between subsequent days of observation. Bud burst occurred earlier on S- than on N-vines in 1978 and 1980 when canes were used that had grown upward while developing as shoots. In 1977, the canes used were not supported vertically while developing as shoots as the complete swing-arm trellis had not yet been installed.

Observations at harvest: Yield per vine in the conversion season 1976 did not differ significantly $(P>0,05)$, with $\mathrm{S}$-vines producing $21,0 \mathrm{~kg}$ and $\mathrm{N}$-vines $15,1 \mathrm{~kg}$ of fresh grapes. In the following four seasons, yield per vine (Fig. 2f) was closely related to bunch number per vine, as mean bunch weight of the two treatments did not differ in any of the seasons. In 1978 yield was affected by a serious hail storm before flowering. The annual mean yield per vine in the four seasons was $28,6 \mathrm{~kg}$ for $\mathrm{S}$ and $21,8 \mathrm{~kg}$ for $\mathrm{N}(\mathrm{P}<0,01)$, despite crop losses due to berry splitting after rain in 1979. The greater number of noncane bunches in $\mathrm{S}$ contributed little to this difference, as the weight of the cane-borne fruit was estimated as 26,6 $\mathrm{kg}$ for $\mathrm{S}$ and $21,3 \mathrm{~kg}$ for $\mathrm{N}$ by assuming that the mean weight on non-cane bunches equalled that of all bunches per vine. This is an overestimate. Fig. 5 shows a typical S- and N-vine at harvest 1980.
Sugar concentration tended to be lower on the S- than on the $\mathrm{N}$-vines in three of the four seasons (Fig. 2h), but the difference reached significance only in 1980 . In this season of comparatively high levels of sugar concentration despite very high yields and early maturity, the $\mathrm{S}$-vines produced 1,57 times more fresh grapes than the $\mathrm{N}$-vines, at a rate of $46,6 \mathrm{tha}^{-1}$. Their yield of sugar was 1,42 times larger despite their lower sugar content $\left(21,9^{\circ}\right.$ as opposed to $24,4^{\circ}$ Brix).

Mean berry weight did not differ significantly in any of the seasons. Berry samples from the N-vines had a higher pH $(3,57$ vs. $3,50, \mathrm{P}<0,05)$ but similar levels of titratable acidity than samples from S-vines in the only season when these measurements were made, 1980.

Observations during pruning: The S-vines produced less one-year-old pruning wood than the $\mathrm{N}$-vines in the three seasons when measurements were made (Table 2). In 1979 , the weight of the two-year-old wood removed from the S-vines was also less. The distribution of shoot growth differed considerably between the two treatments, with less than $15 \%$ of the weight of one-year-old prunings coming from the crown of the $\mathrm{N}$-vines against between 50 and $70 \%$ from the cordons of the S-vines. Consequently, the S-vines had many more canes available for selection as replacement canes. They also had sufficient numbers of canes attached to the vertical wires to restrict selection of the replacement canes to them. 

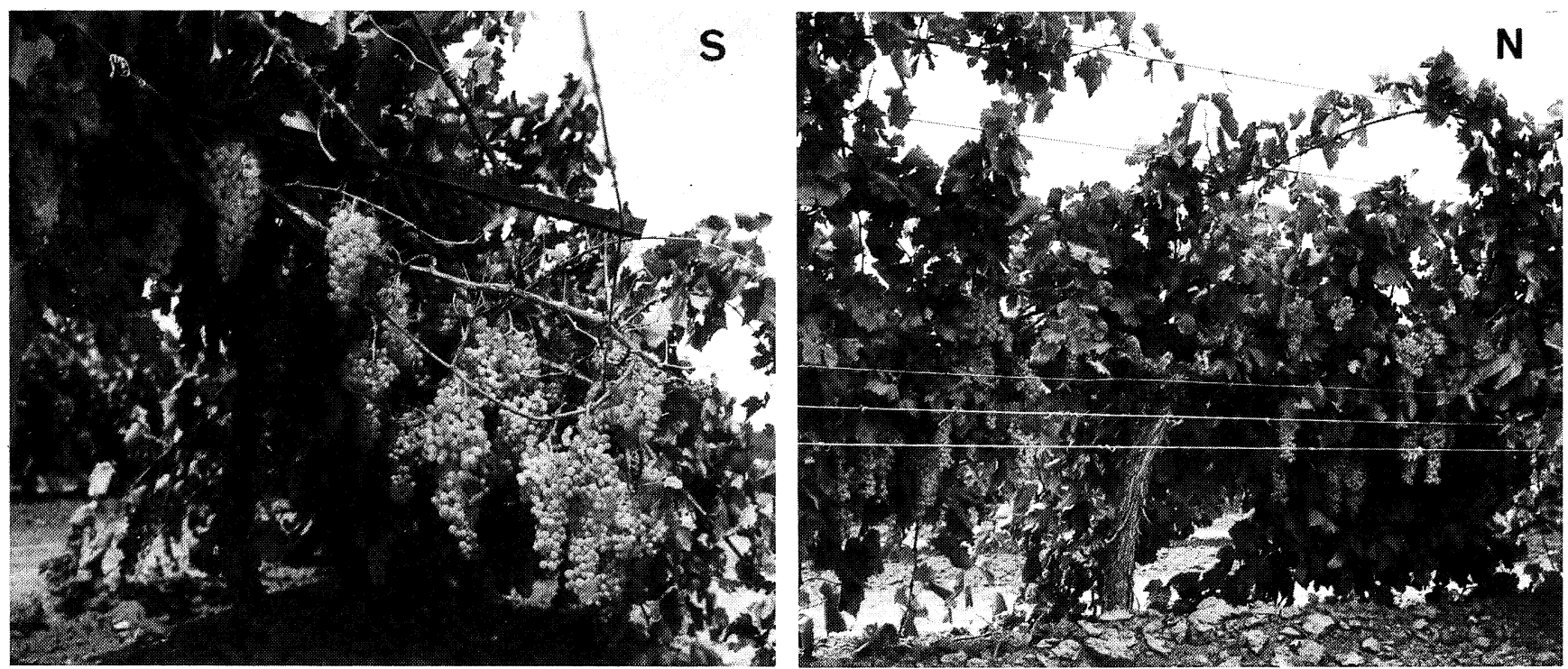

FIG. 5.

S- and N-vines at harvest 1980. Leaves in foreground of S-vine were removed by hand.

TABLE 2 .

Weight of one- and two-year-old pruning wood and number of available replacement canes on S- and N-vines, seasons 1978 to 1980 .

\begin{tabular}{|c|c|c|c|c|c|c|c|c|c|}
\hline & \multicolumn{3}{|c|}{1978} & \multicolumn{3}{|c|}{1979} & \multicolumn{3}{|c|}{1980} \\
\hline & $\mathrm{S}$ & $\mathrm{N}$ & LSD & $\mathrm{S}$ & $\mathrm{N}$ & LSD & $\mathrm{S}$ & $\mathrm{N}$ & LSD \\
\hline $\begin{array}{l}\text { PRUNING WOOD } \\
\text { (kg vine }^{-1} \text { ) } \\
\text { One-year-old, }\end{array}$ & & & & & & & & & \\
\hline $\begin{array}{c}\text { Total } \ldots \ldots \cdots \cdots \\
\text { One-year-old, }\end{array}$ & 1,0 & 1,8 & 0,4 & 3,0 & 4,0 & 0,8 & 1,4 & 2,4 & 0,6 \\
\hline on canes $\ldots \ldots \ldots \ldots \ldots \ldots$ & 一 & 一 & 一 & 1,0 & 3,3 & 0,8 & 0,6 & 2,1 & 0,5 \\
\hline $\begin{array}{l}\text { Two-year-old } \ldots \ldots \ldots \ldots \ldots \ldots \\
\text { REPLACEMENT CANES }\end{array}$ & 一 & 一 & 一 & 0,7 & 1,3 & 0,3 & 1,2 & 1,4 & ns \\
\hline (number vine ${ }^{-1}$ ) $\ldots \ldots \ldots \ldots \ldots$ & - & - & - & & & & & & \\
\hline Total $\ldots \ldots \ldots \ldots \ldots \ldots$ & - & - & - & 22,3 & 10,9 & 3,3 & 18,7 & 9,8 & 3,4 \\
\hline On Vertical wire $\ldots \ldots \ldots \ldots \ldots$ & - & - & - & 12,0 & 2,7 & 1,4 & 9,2 & 2,7 & 3,4 \\
\hline
\end{tabular}

LSD $=$ least significant difference

$\mathrm{ns}=$ not significant

\section{DISCUSSION}

Yield was maintained for S-vines over the four-year period of the experiment. In fact the S-vines produced $31 \%$ more fresh grapes and $25 \%$ more sugar (and thus raisins if the fruit had been dried) than the standard $\mathrm{N}$-vines. The $\mathrm{N}$-vines could not be provided with a standard trellis for practical reasons and they could therefore take advantage of the wider expanse of trellis-wires. They gave similar yields, at least in 1980, to vines in the same row outside the trial, trained with eight canes on a T-trellis $0,3 \mathrm{~m}$ wide $(26,8 \pm 1,9 \mathrm{~kg}$ vs. $27,0 \pm 1,7 \mathrm{~kg})$.

The increased yield of the S-vines was not unexpected, as previous results indicate that yields can be increased by enlarging the foliage canopy, either by widening the trellis (e.g. Shaulis \& May 1971, May, Sauer \& Scholefield 1973, Scholefield, May \& Neales 1977, Sarooshi \& Roberts 1979), or by increasing the height of the canopy by encouraging the replacement shoots to grow upward (May 1966, Scholefield, May \& Neales
1977, Baldwin et al. 1979). Preliminary evidence from other experiments suggests that the S-vines will not suffer as a consequence of the increased yield and reduced vigour of the fruit-bearing shoots. The increased yield was obviously due to a combination of factors-greater trellis support, better exposure of the fruit-bearing shoots and, in particular, greater fruitfulness and better bud development of the replacement canes, a phenomenon observed when limited numbers of canes per vine were trained vertically (May 1966). The behaviour of the vines in 1977 supports the assumption that upward growing, well-exposed canes have a greater yield potential: the canes used as fruiting wood in that season had grown without vertical support on the S-vines as well as the $\mathrm{N}$-vines, and in that season they did not differ in yield, yield components or time of bud burst.

The reduction in sugar concentration in the grapes from the S-vines, particularly during the large, 1980 crop, is somewhat surprising considering the excellent disposi- 
tion of the foliage to the sun. It may have been related to the reduced shoot growth on the canes, as transfer of assimilates seem to occur predominantly within the shoots of a single cane (May, Shaulis \& Antcliff 1969). With trellis drying, differences in the drying ratio associated with differences in sugar concentration do not affect the cost of harvesting.

The greater number of nodes on $\mathrm{S}$ - than on $\mathrm{N}$-canes was presumably due to the S-canes having shorter internodes (as reported for vertical shoots derived from terminal nodes by May (1966)), lying curved on the horizontal wires and following along the outermost, previously uppermost wire. It was not due to differences in the available length of wire support which was $1,25 \mathrm{~m}$ for $\mathrm{N}$ and $0,90 \mathrm{~m}$ for $\mathrm{S}$-canes.

As the vines were not harvest-pruned in this experiment, it was not possible to determine whether this practice would cause yield losses on S-vines similar to those experienced at times on standard vines (Scholefield, May \& Neales 1977). The large number of shoots arising on the cordon that would remain on the vine after harvest-pruning may well prevent or at least reduce such losses. On the other hand, the greater number of non-cane bunches would increase the cost of trellis-drying as they would have to be picked separately by hand. Their removal before flowering, perhaps combined with positioning and thinning of the cordon-shoots, maybe advantageous as has been suggested for standard vines by Sarooshi and Roberts (1979). Crop reductions incurred in this way could be avoided by leaving additional nodes on the canes.

Mechanical methods of harvesting and pruning were not tested in the experiment. For raisin production, severance of the canes either by hand or mechanically, would be facilitated by the separation of the zones of fruiting and replacement shoots (May et al. 1978). This would also improve the coverage of the bunches with alkaline drying emulsion (Clingeleffer et al. 1977) possibly after pneumatic defoliation of the fruit-bearing shoots. As posts or trunks do not obstruct, fresh fruit or trellis dried raisins could be collected by a single-sided mechanical harvester, such as a modification of the raspberry harvester designed by Dunn (1974) which has given excellent results with grapes (Anon. 1980), or the harvesters designed for grape pergolas by Dipaola, Arrivo \& Grittani (1977) or Calo' et al. (1979). Such harvesters should have advantages over the large, expensive machines in use at present, particularly for the smaller grower. During winter-pruning, cane-removal and canetrimming could also be done mechanically. Canes not attached to the wire would need to be spurred or completely removed, but restriction of cane numbers per vine, based on experience in previous experiments (Antcliff 1965, May, Sauer \& Scholefield 1973), appears to be unnecessary.

The experiment did not test different methods of construction of a swing-arm trellis. The design used in the present experiment was simple, not more expensive to erect than some of the more elaborate trellises proposed for trellis drying (e.g. Baldwin et al. 1979) and resisted the stresses of uneven load and wind. Much more extensive tests would be necessary, however, to determine its commercial suitability. Compared with the original design by Dunn (1974) and a design proposed by James
(1978), it has the advantage that it can be installed in an existing, trellised vineyard. In part, it resembles the one-sided pergola used in Italy or the slanting trellis of South African table grape vineyards.

Although the use of the swing-arm trellis has only been discussed in connection with the Sultana vines, it should also be useful for other varieties of low fruitfulness at the base of their canes.

\section{LITERATURE CITED}

ANONYMOUS, 1980. Raspberry harvester used in grape industry trial. Aust. Grapegrower Winemaker no. 199, 7.

ANTCLIFF, A. J., 1965. A comparison of cropping levels in the sultana, Vitis 5, 1-9.

ANTCLIFF, A. J. \& HAWSON, H., 1974. The Australian sultana clones: rapid adoption of improved planting material. J. Aust. Inst. agric. Sci. 40, 109-113.

ANTCLIFF, A. J., MAY, P., WEBSTER, W. J. \& HAWKES, J., 1972. The Merbein bunch count, a method to analyze the performance of grapevines. Hort. Science 7, 196-197.

BALDWIN, J. G., BLEASDALE, G. E., CADMAN, R. S. \& KEENS, I. L., 1979. Comparison of trellises and pruning levels for Sultana vines in the Murray Valley. Aust. J. exp. Agric. Anim. Husb. 19, 634-640.

CALO', A., IANNINI, B., LAVEZZI, A., ALPAGO, R., PICCOLI, P., 1979. Esperienze di vendemmia meccanica in allevamenti a pergola, con l'impiego di una nuova testa di raccolta. Riv. Yiticolt. Enol. 32, 123-129.

CLINGELEFFER, P. R., TRAYFORD, R. S., MAY, P. \& BRIEN, C. J., 1977. Use of the starwheel sprayer for applying drying emulsion to Sultana grapes to be dried on the trellis. Aust. J. exp. Agric. Anim. Husb. 17, 871-880.

DIPAOLA, G., ARRIVO, A. \& GRITTANI, P., 1977. A new wine grape harvester designed by the Institute of Agricultural Mechanics Engineering of Bari University, for flat vineyard (quanti-qualitative aspects). In: International symposium on the quality of the vintage, Cape Town. (Oenological and Viticultural Research Institute: Stellenbosch) 467-472.

DUNN, J. S., 1974. Mechanical harvesting of apples and raspberries: An agronomic approach. Span 17, 112-113.

JAMES, K., 1978. The Irymple trellis for grapes. In: "Survey of Research and Investigations in Agriculture Engineering 1978" (Institution of Engineers, Australia: Barton, A. C. T.) p. 119.

MAY, P., 1965. The effect of different methods of attaching sultana canes to the trellis wire. Aust. J. exp. Agric. Anim. Husb. 5, 87-90.

MAY, P., 1966. Effect of direction of shoot growth on fruitfulness and yield of sultana vines. Aust. J. agric. Res. 17, 479-490.

MAY, P., 1976. Workshop on mechanical harvesting of wine and drying grapes. Aust. Grapegrower Winemaker, no. 148: $16-18,20,22$.

MAY, P. \& CLINGELEFFER, P. R., 1977: Mechanical pruning of grape vines. Aust. Wine Brew. Spirit Rev. 96, 36-38.

MAY, P., CLINGELEFFER, P. R., BRIEN, C. J. \& SCHOLEFIELD, P. B., 1978. Harvest pruning of young Sultana vines under various training systems. Aust. J. exp. Agric. Anim. Husb. 18, 847-854.

MAY, P. \& KERRIDGE, G. H., 1967. Harvest-pruning of Sultana vines. Vitis 6, 390-393.

MAY, P., SAUER, M. R. \& SCHOLEFIELD, P. B., 1973. Effect of various combinations of trellis, pruning and rootstocks on vigorous Sultana vines. Vitis, 12, 192-206.

MAY, P., SCHOLEFIELD, P. B., CLINGELEFFER, P. R. \& SMITH, L., 1974. Experiments on the mechanical harvesting of sultanas for drying. J. Sci. Fd. Agric. 25, 541-552. 
MAY, P., SHAULIS, N. J. \& ANTCLIFF, A. J., 1969. The effect of controlled defoliation in the sultana vine. Am. J. Enol. Vitic. 20, 237-250.

SAROOSHI, R. A. \& ROBERTS, E. A., 1979. Effect of trellising, crown bunch handling, and the number of oil emulsion and gibberellic acid sprays on harvest-pruned Sultanas. Aust. J. exp. Agric. Anim. Husb. 19, 122-128.
SCHOLEFIELD, P. B., MAY, P. \& NEALES, T. F., 1977. Harvest-pruning and trellising of "Sultana" vines. I. Effects on yield and vegetative growth. Scientia Hortic. 7, 115-122.

SHAULIS, N. J. \& MAY, P., 1971. Response of "Sultana" vines to training on a divided canopy and to shoot crowding. Am. J. Enol. Vitic. 22, 215-222. 